\title{
Temperature and Leaf Wetness Requirements for Pathogen Establishment, Incubation Period, and Sporulation of Phytophthora infestans on Petunia $\times$ hybrida
}

\author{
M. C. Becktell, Department of Plant Pathology, Cornell University, Ithaca, NY 14853; M. L. Daughtrey, Long \\ Island Horticultural Research and Extension Center, Cornell University, Riverhead, NY 11901; and W. E. Fry, \\ Department of Plant Pathology, Cornell University, Ithaca, NY 14853
}

\begin{abstract}
Becktell, M. C., Daughtrey, M. L., and Fry, W. E. 2005. Temperature and leaf wetness requirements for pathogen establishment, incubation period, and sporulation of Phytophthora infestans on Petunia $\times$ hybrida. Plant Dis. 89:975-979.

The temperature and leaf wetness requirements for pathogen establishment (germination, infection, and colonization) and the temperature effects on incubation period and sporulation of Phytophthora infestans on petunia were compared with those on tomato. The responses to environmental parameters were found to be similar on petunia and tomato and agreed with those previously reported for late blight development on tomato and potato. In the current study, temperatures ranging from 13 to $23^{\circ} \mathrm{C}$ generally were conducive to establishment. Very little establishment occurred at $28^{\circ} \mathrm{C}$. The minimum leaf wetness period that enabled pathogen establishment was $2 \mathrm{~h}$, whereas most establishment occurred within $6 \mathrm{~h}$ of inoculation. The incubation period (time period from inoculation to lesion development) and the time required for development of sporangia after lesions were formed were shortest at 23 and $28^{\circ} \mathrm{C}$, respectively. Production of sporangia was greatest (per square centimeter) at $18^{\circ} \mathrm{C}$ and was nearly absent at $28^{\circ} \mathrm{C}$ on both petunia and tomato. The sporulation density at $18^{\circ} \mathrm{C}$ was only slightly less on petunia compared with tomato $\left(20,000\right.$ and 24,000 sporangia $/ \mathrm{cm}^{2}$, respectively); however, the total lesion area on petunia was only $20 \%$ of that on tomato.
\end{abstract}

Temperature and moisture play major roles in the epidemiology of late blight. These environmental factors determine whether a sporangium will produce a germ tube or zoospores, how successful the pathogen will be at establishing a parasitic interaction with the host, and the rate at which the pathogen can grow through the host tissue. Environmental conditions influence pathogen establishment, the incubation period (time period from inoculation to lesion development), and the timing and production of sporangia and, thus, determine whether pathogen establishment will occur at all.

The environmental requirements for the development of late blight on potato have been determined previously $(1,4,6,12)$; requirements for late blight on tomato have been studied less extensively $(4,6)$. On potato, the establishment of Phytophthora

Corresponding author: M. C. Becktell

E-mail: mbecktel@mesastate.edu

This work was supported by the Department of Plant Pathology at Cornell University and in part by the Fred C. Gloeckner Foundation.

Current address of M. C. Becktell: Mesa State College, Department of Biological Sciences, Grand Junction, CO 81501.

Accepted for publication 2 May 2005.

DOI: 10.1094/PD-89-0975

(C) 2005 The American Phytopathological Society infestans requires a minimum of 2 to $3 \mathrm{~h}$ of leaf wetness at the optimum temperature of $20^{\circ} \mathrm{C}$ (6), incubation period is shortest between 20 and $28^{\circ} \mathrm{C}(1,6,12)$, the most rapid sporangium production after lesions have formed occurs at around $21^{\circ} \mathrm{C}$ (6), and the optimum temperature range for maximum sporangia/unit area is 15 to $21^{\circ} \mathrm{C}(1,6,12)$. On tomato, Berg (4) found that pathogen establishment required more than $3 \mathrm{~h}$ of leaf wetness; Crosier (6) confirmed Berg's findings and determined that the optimum temperature range for incubation period on tomato was 20 to $23^{\circ} \mathrm{C}$.

Investigations in our lab on the susceptibility of Petunia $\times$ hybrida (petunia) (2), along with recent occurrences of petunia late blight $(3,7,8)$, suggest that petunia plants could have a significant impact on the epidemiology of potato and tomato late blight by serving as sources of inoculum for epidemics on these hosts. Petunia and tomato both are greenhouse crops; therefore, the potential for spread between these two hosts is of particular concern. Very little is known of petunia late blight and nothing has been reported regarding the environmental requirements for this system. However, in order to develop an integrated management system for late blight on petunia and other plants, an accurate understanding of the environmental factors affecting disease development is required. Therefore, the objective of this study was to learn the effect of temperature and moisture on petunia late blight compared with the requirements for tomato late blight. Specifically, we determined (i) the effects of temperature and moisture on pathogen establishment and (ii) the effect of temperature on incubation period and sporangium production and density.

\section{MATERIALS AND METHODS}

Plant material. Four- to five-week-old petunia (cv. White Madness) and tomato (cv. Sunrise) plants were used. The petunia plants were seeded into flats ( 25 by $46 \mathrm{~cm}$ ) containing eight "six-packs". Individual six-packs containing 12 to 30 plants (depending on germination rates) were used as experimental units. Tomato plants (used for comparison purposes) were seeded into 4-in. (10.16-cm) plastic pots (two plants per pot). Seeds were planted in the greenhouse in a soilless mix (Cornell mix) consisting of 1:2:2 ( $\mathrm{vol} / \mathrm{vol})$ perlite:peat: vermiculite with $4 \mathrm{~kg}$ of dolomitic limestone, $0.33 \mathrm{~kg}$ of nitrogen $(\mathrm{N})$ and potassium $\left(\mathrm{K}_{2} \mathrm{O}\right)$, and $0.16 \mathrm{~kg}$ of phosphate $\left(\mathrm{P}_{2} \mathrm{O}_{5}\right)$ per cubic meter of mix. Natural sunlight was supplemented with $400-\mathrm{W}$ high-pressure sodium lamps on a 12-h cycle of light and dark. Temperatures were maintained between 24 and $29^{\circ} \mathrm{C}$. The plants were fertilized once or twice a week with liquid fertilizer containing nitrogen at 200 to $300 \mathrm{ppm}$.

$P$. infestans isolate, inoculum preparation, and inoculations. Isolate US970001 of the US-17 clonal lineage (mating type A1) was used for all inoculations; the isolate originally was obtained from tomato plants in Florida in 1997 and subsequently maintained in the culture collection at Cornell University on rye agar medium (5). This isolate was chosen based on previous work in the lab that proved its reliability of sporulation in culture and on tomato leaflets as well as its consistent infection of both petunia and tomato (2). Inoculum was produced on detached tomato leaflets (cv. Sunrise). Sporangia were rinsed from the leaflets into $100 \mathrm{ml}$ of distilled water and the concentration of sporangia was determined (as the average of three readings) with a hemacytometer and adjusted as needed. The sporangial suspension was incubated at $4^{\circ} \mathrm{C}$ for 1 to 2 $\mathrm{h}$ to induce zoospore production. All plants were spray inoculated to run-off with sporangium or zoospore suspensions $(10,000$ to 20,000 sporangia/ml) with a handheld sprayer. 
Pathogen establishment. The effect of temperature and leaf wetness on establishment of $P$. infestans in petunia and tomato foliage was determined. The temperatures chosen $\left(13,18,23\right.$, and $\left.28^{\circ} \mathrm{C}\right)$ corresponded to temperatures used in previous studies of potato and tomato late blight $(1,6,10,12)$ and also reflected temperatures used for commercial greenhouse production of petunia and tomato plants (9). The experiments were conducted between July 2002 and August 2003. A splitplot design was used in which temperature represented the whole-plot treatment factor and leaf wetness period represented the subplot units within each temperature. In a preliminary experiment in which inoculated plants were incubated at $100 \%$ relative humidity (RH) for $0,2,4,6,8,10$, or $12 \mathrm{~h}$, we found that most establishment occurred within $6 \mathrm{~h}$ (data not shown), results that agreed with previous work on potato late blight (6). Therefore, subsequent experiments included incubation periods of $0,2,4$, or $6 \mathrm{~h}$ only. Following inoculation, plants were placed in a growth chamber at $13,18,23$, or $28^{\circ} \mathrm{C}$ under conditions of $100 \%$ RH. Saturated RH was established and maintained in the growth chamber with tents (consisting of a PVC frame covered with semiclear plastic sheeting) containing a Trion automatic humidi-
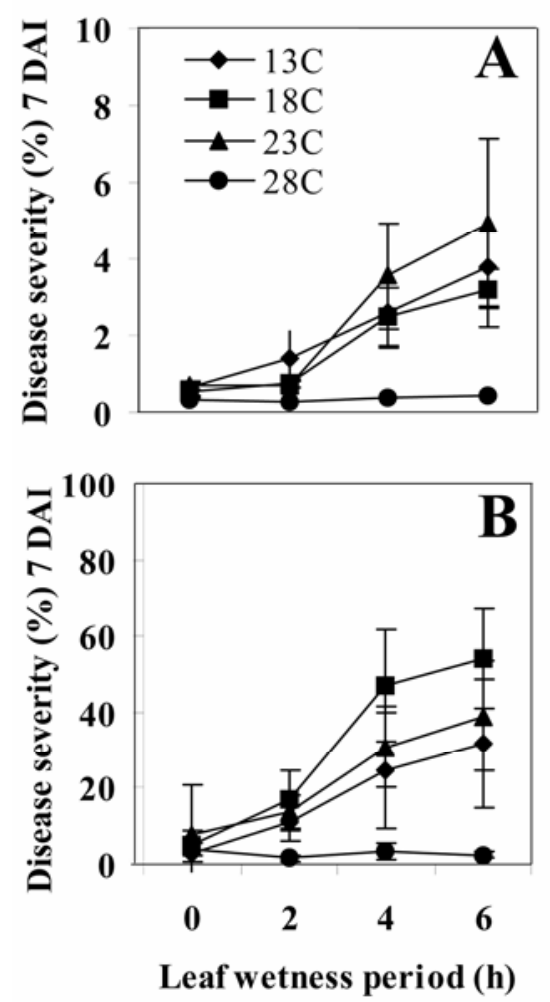

Fig. 1. Effect of temperature and leaf wetness period on disease severity on $\mathbf{A}$, petunia and $\mathbf{B}$, tomato 7 days after inoculation (DAI). Error bars represents the standard error of the mean percent disease of three six-packs of petunia plants and six trials $(n=18)$ or one tomato plant and six trials $(n=6)$. fier (model 500; Hummert International, Earth City, MO) that ran periodically throughout the day. Every $2 \mathrm{~h}$, three sixpacks of petunia plants and one pot of tomato plants, representing a single experimental unit, were moved to a second incubation chamber $\left(15^{\circ} \mathrm{C}, 90 \% \mathrm{RH}\right)$. Humidity within this incubation chamber was achieved with a Sunbeam ultrasonic humidifier (Sunbeam Products, Inc., Boca Raton, FL) and a humidity tent as described above. The temperature and relative humidity within each of the two chambers were monitored with a Hobo H8 Pro RH/Temp data logger (Onset Computer Corporation, Bourne, MA).

A complete set of temperatures and leaf wetness periods was considered one trial. Each trial was conducted over a 4-day period, with each day dedicated to one particular temperature. A total of six trials was conducted. A visual assessment of disease severity (11) (proportion of plant area infected) was made for each petunia six-pack and each pot of tomato plants seven days after inoculation (DAI).

Incubation period. The effect of temperature on the incubation period for petunia and tomato late blight was determined. The experiments were conducted between August and October 2002. Petunia and tomato plants were inoculated in a humid growth chamber as described above. Inoculated plants were kept at $15^{\circ} \mathrm{C}$ and $100 \% \mathrm{RH}$ for $24 \mathrm{~h}$ to allow for maximum pathogen establishment. After $24 \mathrm{~h}$, four sets of plants were moved to four individual chambers at $100 \%$ RH with temperatures set to $13,18,23$, or $28^{\circ} \mathrm{C}$. Saturated $\mathrm{RH}$ within each chamber was achieved with Sunbeam ultrasonic humidifiers (Sunbeam Products, Inc., Boca Raton, FL) or Holmes 1-gal cool-mist impeller humidifiers (Holmes Products, Inc., El Paso, TX). Each set of plants represented a single experimental unit and consisted of one flat of petunia plants (containing eight sixpacks) and one pot of tomato plants. The plants were checked twice a day at 8 -h intervals (morning and evening) for lesion development. The time at which the first lesions were visible was recorded. The incubation periods of the eight six-packs of petunia plants within a flat were recorded, then averaged; this number was used for data analysis. The temperature and relative humidity within each chamber were monitored with a Hobo H8 Pro RH/Temp data logger. The experiment was conducted five times.

Sporulation. The effect of temperature on sporulation timing was determined. In this experiment, sporulation timing was defined as the time required for sporangia to be formed on newly formed, nonsporulating petunia and tomato late blight lesions. The methods used were similar to those of Hartill et al. (10). The experiments were conducted between October and November 2002. Petunia and tomato plants were inoculated in a humid chamber as described above. Inoculated plants were incubated at $15^{\circ} \mathrm{C}$ and $100 \% \mathrm{RH}$ and checked daily. At the first sign of lesion development ( 3 to $5 \mathrm{DAI}$ ), the plants were moved to a chamber with an average $\mathrm{RH}$ of $80 \%$ to promote lesion expansion without sporulation. After 24 to $48 \mathrm{~h}$ at $80 \%$ $\mathrm{RH}$, one experimental unit of plants, consisting of one six-pack of petunia plants and one pot of tomato plants, was moved to one of four separate incubators $(13,18$, 23 , or $\left.28^{\circ} \mathrm{C}, 100 \% \mathrm{RH}\right)$. Every 2 to $4 \mathrm{~h}$, three to six leaves with lesions were excised from plants at each temperature and inspected microscopically for the appearance of sporangia.

The effect of temperature on sporulation density (sporangia/ $\mathrm{cm}^{2}$ ) was determined. At $24 \mathrm{~h}$ after sporangia were first detected at each temperature, the number of sporangia per unit of lesion area was measured. Four leaves with sporulating lesions were collected from both petunia and tomato at each temperature and the sporangia were rinsed off into $20 \mathrm{ml}$ of distilled water. The concentration of sporangia/ml was determined (as the average of at least three readings) with a hemacytometer. To determine the lesion area $\left(\mathrm{cm}^{2}\right)$, digital images of the leaves and UTHSCSA ImageTool software (University of Texas Health Science Center, San Antonio, TX) were used. Sporulation density then was calculated by dividing the total number of sporangia (sporangia/ml $\times 20 \mathrm{ml}$ ) by the total lesion area on the four sampled leaves.

Statistical analyses. All statistical analyses were performed using Statistical Analysis System (version 8.2; SAS Institute, Cary, NC) and SPSS statistical software (version 11.5; SPSS Inc., Chicago). The effects of temperature and leaf wetness period on disease severity in the pathogen establishment experiments were tested with an analysis of variance. The split-plot linear model was $y_{\mathrm{ijk}}=\mu+\alpha_{\mathrm{i}}+$ $\rho_{\mathrm{k}}+d_{\mathrm{ik}}+\beta_{\mathrm{j}}+(\alpha \beta)_{\mathrm{ij}}+\varepsilon_{\mathrm{ijk}}$, where $\mu$ is the overall mean, $\alpha_{\mathrm{i}}$ is the effect of the $i$ th temperature, $\rho_{\mathrm{k}}$ is the effect of the $k \mathrm{th}$ block (trial), $d_{\mathrm{ik}}$ is the whole-plot random error; $\beta_{\mathrm{j}}$ is the effect of the $j$ th leaf wetness period, $(\alpha \beta)_{\mathrm{ij}}$ is the interaction between temperature and leaf wetness period, and $\varepsilon_{\mathrm{ijk}}$ is the subplot random error. Residual plots (predicted values versus standardized observed values) and normal probability plots were used to check the data for normality and homogeneity of variance. An arcsine of the square root transformation was performed on the pathogen establishment data. Regression analyses to determine the relationship between temperature and leaf wetness period were performed using the curve estimation function in SPSS.

A one-way analysis of variance (ANOVA) was performed on the means from the incubation period, lesion area, 
and sporulation data. When significant effects were indicated by the ANOVA, regression analyses were used to explore the relationship of temperature, leaf wetness period, or both on pathogen establishment, incubation period, and sporulation. The homogeneity of variance was checked using a Levene test. A square root transformation was performed on the sporulation density data for tomato.

\section{RESULTS}

Pathogen establishment. $P$. infestans became established very rapidly on both hosts. Temperature and duration of leaf wetness (Fig. 1) clearly influenced establishment of $P$. infestans on both petunia $(P$ $<0.005)$ and tomato $(P<0.01)$. The interaction of temperature and leaf wetness period was stronger on petunia $(P=$ $0.0002)$ than on tomato $(P=0.1090)$; however, regression analyses of the interaction on the two hosts gave similar results (Table 1). The effect of temperature on pathogen establishment at each leaf wetness period was quadratic (Fig. 2A and B), with predicted optimum temperatures for maximum pathogen establishment on both hosts ranging from 18 to $21^{\circ} \mathrm{C}$ at all leaf wetness periods. The effect of leaf wetness period on pathogen establishment at each temperature was linear (Fig. 2C and D). Pathogen establishment increased with increasing leaf wetness periods at all temperatures except $28^{\circ} \mathrm{C}$. There was little to no pathogen establishment at $28^{\circ} \mathrm{C}$, regardless of leaf wetness period. On both petunia and tomato plants, most establishment occurred within the first $6 \mathrm{~h}$ of leaf wetness, but required at least $2 \mathrm{~h}$ of leaf wetness (Fig. 1; Table 1). Some plants became infected even when they were not incubated at $100 \%$ RH (Fig. 1).

Incubation period. The incubation period (following a 24-h pathogen establish- ment period at $15^{\circ} \mathrm{C}$ ) decreased significantly as temperature increased from 13 to $28^{\circ} \mathrm{C}$ for both petunia and tomato. The shortest incubation period was less than 3 days and occurred at $28^{\circ} \mathrm{C}$ (Fig. 3). Late blight lesions on each host were distinctive, regardless of temperature. Petunia late blight lesions were necrotic and irregularly shaped; sporulation was limited to the necrotic lesion area. In contrast, tomato late blight lesions typically started as collapsed tissue that often encompassed an entire leaflet; sporulation often was visible across the entire abaxial surface of the infected leaflet.

A regression analysis suggested that a quadratic equation best explains the relationship of temperature to incubation period on both petunia and tomato $\left(R^{2}=\right.$ 0.993 for petunia and tomato).

Sporulation timing and density. Temperature had a complex effect on the time required for the development of sporangia from lesions on both hosts. The emergence of aerial hyphae and the development of sporangia were readily observed microscopically. At $28^{\circ} \mathrm{C}$, aerial hyphae were observed, but sporangia were not. At 13 , 18 , or $23^{\circ} \mathrm{C}$, the time required for sporangia to appear was between 6 and $9 \mathrm{~h}$ (Fig. 4A). Based on a linear regression analysis, the individual petunia and tomato slopes did not differ significantly from zero. However, there appeared to be a slight trend (slope $=-0.15, P=0.113$ ) in the combined petunia and tomato data that indicated a decrease in sporulation time with increasing temperature. There was no significant interaction between the petunia and tomato data.

Temperature had a significant effect $(P$ $=0.001)$ on the quantity of sporangia produced on petunia and tomato late blight lesions. The sporulation density (sporan$\mathrm{gia} / \mathrm{cm}^{2}$ ) for each host was highest at $18^{\circ} \mathrm{C}$

Table 1. Regression analyses of the interaction between temperature (T) and leaf wetness (LW) period during pathogen establishment of Phytophthora infestans on petunia and tomato

\begin{tabular}{cccccc}
\hline & \multicolumn{5}{c}{ Regression analysis results } \\
\cline { 2 - 6 } Effect $^{\mathbf{a}}$ & $\boldsymbol{R}^{\mathbf{2}}$ & $\boldsymbol{b}_{\mathbf{0}}$ & $\boldsymbol{b}_{\mathbf{1}}$ & $\boldsymbol{b}_{\mathbf{2}}$ & $\boldsymbol{P}>\boldsymbol{F}$ \\
\hline $\mathrm{LW} \times \mathrm{T}$ & & & & & \\
$13^{\circ} \mathrm{C} p$ & 0.270 & 0.681 & 0.173 & $\ldots$ & 0.009 \\
$13^{\circ} \mathrm{C} t$ & 0.171 & 2.062 & 5.264 & $\ldots$ & 0.044 \\
$18^{\circ} \mathrm{C} p$ & 0.575 & 0.576 & 0.184 & $\ldots$ & 0.000 \\
$18^{\circ} \mathrm{C} t$ & 0.394 & 3.7967 & 8.927 & $\ldots$ & 0.001 \\
$23^{\circ} \mathrm{C} p$ & 0.335 & 0.659 & 0.204 & $\ldots$ & 0.003 \\
$23^{\circ} \mathrm{C} t$ & 0.244 & 5.739 & 5.641 & $\ldots$ & 0.017 \\
$28^{\circ} \mathrm{C} p$ & 0.011 & 0.410 & 0.015 & $\ldots$ & 0.622 \\
$28^{\circ} \mathrm{C} t$ & 0.004 & 3.053 & -0.107 & $\ldots$ & 0.756 \\
$\mathrm{~T} \times \mathrm{LW}$ & & & & & \\
$0 \mathrm{~h} p$ & 0.074 & -0.277 & 0.107 & -0.002 & 0.444 \\
$0 \mathrm{~h} t$ & 0.082 & -71.432 & 7.940 & -0.185 & 0.408 \\
$2 \mathrm{~h} p$ & 0.275 & -0.326 & 0.130 & -0.004 & 0.040 \\
$2 \mathrm{~h} t$ & 0.194 & -47.284 & 6.812 & -0.181 & 0.104 \\
$4 \mathrm{~h} p$ & 0.363 & -2.045 & 0.412 & -0.011 & 0.009 \\
$4 \mathrm{~h} t$ & 0.372 & -212.54 & 25.636 & -0.643 & 0.010 \\
$6 \mathrm{~h} p$ & 0.302 & -2.357 & 0.474 & -0.013 & 0.023 \\
$6 \mathrm{~h} t$ & 0.298 & -146.95 & 21.393 & -0.574 & 0.024 \\
\hline
\end{tabular}

${ }^{\text {a Petunia }}(p)$ and tomato $(t)$ regression results for each temperature or leaf wetness period. $\mathrm{LW} \times \mathrm{T}=$ effect of $\mathrm{LW}$ period at $\mathrm{T}$ of $13,18,23$, and $28^{\circ} \mathrm{C} ; \mathrm{T} \times \mathrm{LW}=$ effect of $\mathrm{T}$ at $0,2,4$, and $6 \mathrm{~h}$ of $\mathrm{LW}$.

and lowest at $28^{\circ} \mathrm{C}$ (Fig. 4B). At $18^{\circ} \mathrm{C}$, petunia lesions produced an average of 20,000 sporangia/ $\mathrm{cm}^{2}$ compared with tomato late blight lesions that produced an
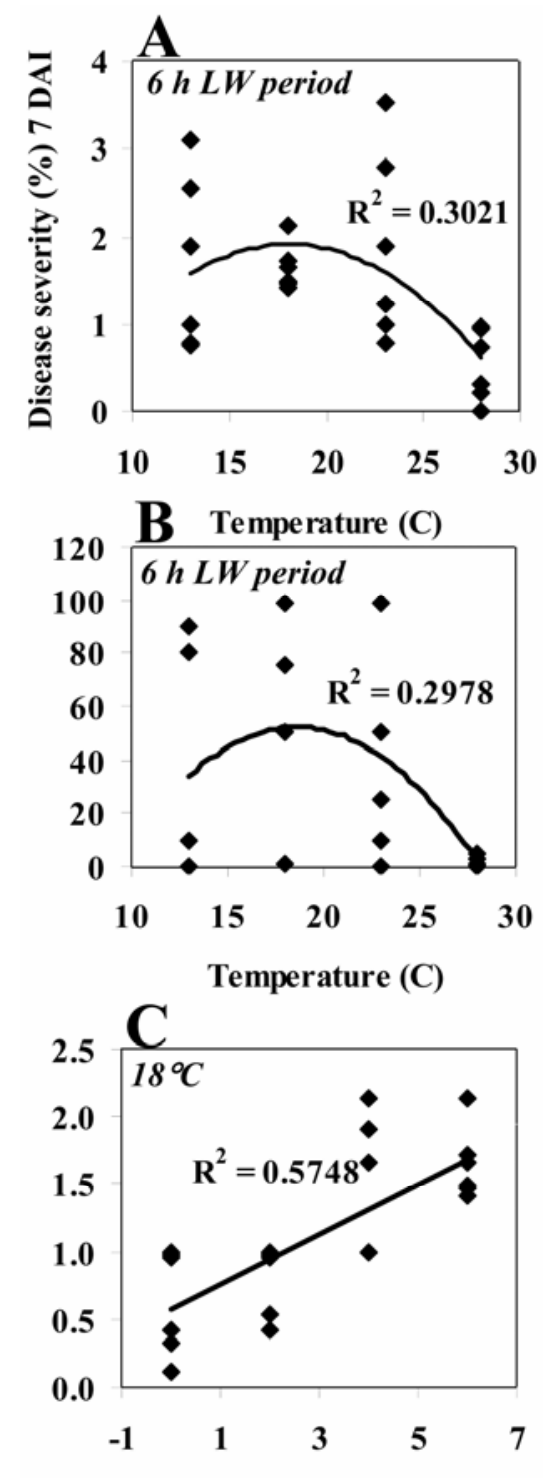

Leaf wetness period $(\mathrm{h})$



Fig. 2. Representative regression plots showing the effects of temperature and leaf wetness period on pathogen establishment. Effect of temperature at $6 \mathrm{~h}$ of leaf wetness on $\mathbf{A}$, petunia and $\mathbf{B}$, tomato. Effect of leaf wetness at $18^{\circ} \mathrm{C}$ on $\mathbf{C}$, petunia and $\mathbf{D}$, tomato. 
average of 24,000 sporangia $/ \mathrm{cm}^{2}$. However, the average lesion area, over all temperatures and trials, was significantly smaller on petunia than on tomato $(P<$ 0.001; Fig. 4C), with a total mean lesion area of 5 and $31 \mathrm{~cm}^{2}$ on petunia and tomato, respectively.

Regression analyses showed that the relationship of temperature to sporulation density was best explained by a quadratic equation. For petunia, the equation was $y=$ $-32.40+5.80 \times T-0.16 \times T^{2}\left(R^{2}=0.987\right)$. For tomato, the equation was $y=9.26+$ $2.21 \times T-0.09 \times T^{2}\left(R^{2}=0.961\right)$.

\section{DISCUSSION}

This is the first report on the effects of temperature and moisture on petunia late blight compared directly with tomato late blight. The results show that the effects of leaf wetness, temperature, or both on establishment, incubation period, and sporulation of $P$. infestans on petunia are similar to those previously reported in the literature on potato and tomato late blight $(1,4,6,10,12)$.

In the current study on petunia and tomato, most pathogen establishment occurred between 13 and $23^{\circ} \mathrm{C}$, with a predicted optimum between 18 and $21^{\circ} \mathrm{C}$. In addition, pathogen establishment occurred within $6 \mathrm{~h}$ of leaf wetness but required a minimum leaf wetness period of $2 \mathrm{~h}$ following inoculation. Previous work on potato and tomato has demonstrated that establishment of $P$. infestans requires 2 to $3 \mathrm{~h}$ of leaf wetness at temperatures between 20 and $23^{\circ} \mathrm{C}(4,6)$. Interestingly, in our study, some successful infections occurred even when the plants were withdrawn from $100 \%$ RH immediately after inoculation; these results presumably were due to the presence of residual water from the inoculations.

We found that, after the pathogen gained ingress, the subsequent incubation period

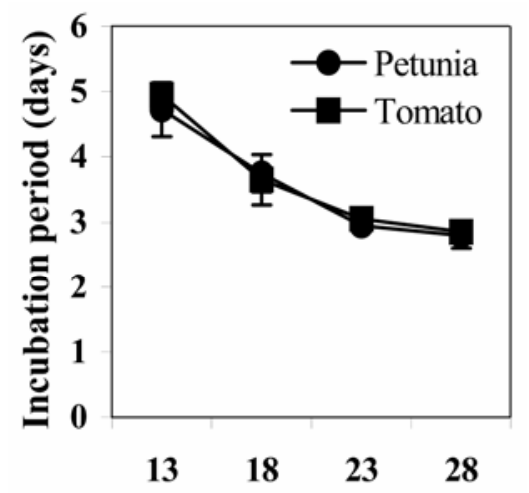

Temperature (C)

Fig. 3. Effect of temperature on the incubation period of late blight on petunia and tomato. The plants were given a 24-h pathogen establishment period at $15^{\circ} \mathrm{C}$ prior to incubation at the four temperatures. The error bars represent the standard error of the mean incubation period of eight six-packs of petunia plants and five trials $(n=40)$ or one tomato plant and five trials $(n=5)$. tended to shorten as temperature increased from 13 to $28^{\circ} \mathrm{C}$. The shortest incubation period occurred at $28^{\circ} \mathrm{C}$. Existing literature on the environmental requirements for potato and tomato late blight reports that incubation period is shortest between 20 and $28^{\circ} \mathrm{C}(1,6,12)$.

This is the first report on the effects of temperature on sporulation dynamics and density on petunia and tomato late blight lesions. We found that there was very little difference in time required for sporulation at temperatures between 13 and $23^{\circ} \mathrm{C}$ ( 6 to $9 \mathrm{~h}$ ), but that there was a slight trend toward more rapid sporulation of $P$. infestans at $23^{\circ} \mathrm{C}$ on both petunia and tomato. Crosier (6) determined that the optimum temperature for rapidity of sporulation on potato late blight lesions ranged from 18 to $22^{\circ} \mathrm{C}$. In addition, Hartill et al. (10) dem-
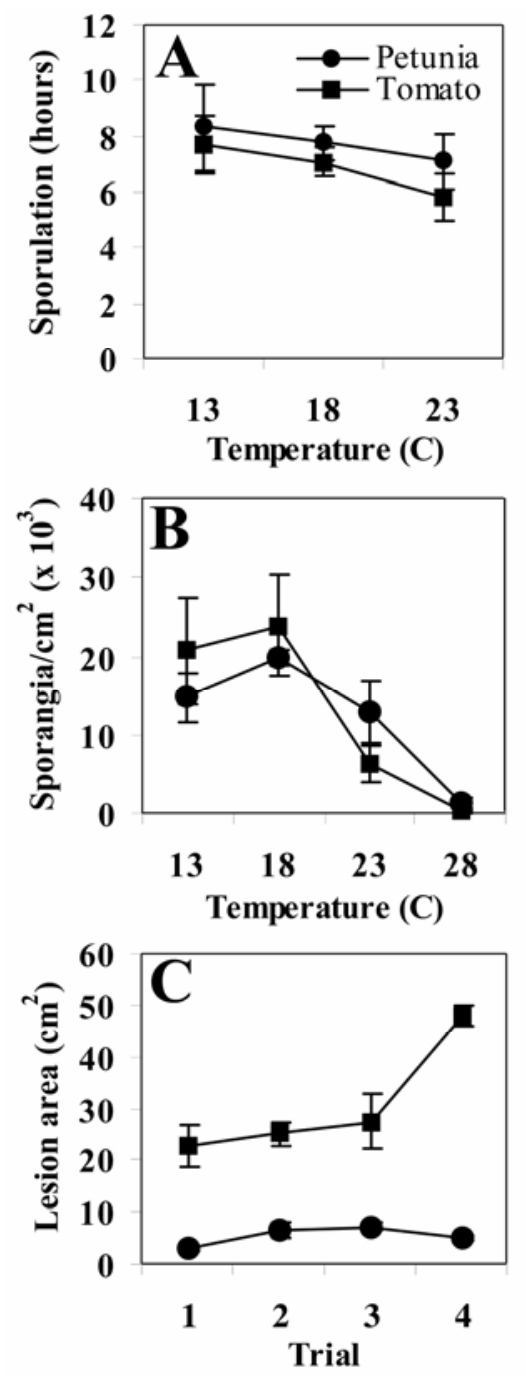

Fig. 4. Effect of temperature on A, sporangium development time and $\mathbf{B}$, sporulation density (sporangia/ $\mathrm{cm}^{2}$ ) of Phytophthora infestans on petunia and tomato. Error bars represent the standard error of the mean time or sporulation density of four leaves and four trials $(n=16)$. C, Comparison of late blight lesion area on petunia and tomato plants over all temperatures in each of four trials. Error bars represent the standard error of the mean lesion area of 16 leaves $(n=16)$. onstrated that the sporulation time for $P$. infestans on potato decreases with increasing temperatures between 5 and $22^{\circ} \mathrm{C}$, but that sporangium development time between 13 and $23^{\circ} \mathrm{C}$ did not differ significantly. The maximum sporulation density (sporangia $/ \mathrm{cm}^{2}$ ) on both petunia and tomato occurred at $18^{\circ} \mathrm{C}$ in our study and was within the range of temperatures (15 to $22^{\circ} \mathrm{C}$ ) determined previously for maximum sporulation density on potato $(1,6,12)$.

Based on our study and the existing literature on tomato and potato late blight, we can conclude that the temperature and moisture requirements for late blight development on petunia plants do not differ dramatically from those of potato and tomato late blight. However, petunia plants are far less susceptible to late blight than either potato or tomato (13). In the current study, disease severity on petunia was consistently only about $10 \%$ of the disease severity on tomato, and lesion area on petunia plants typically was only $20 \%$ of that on tomato plants. It appears that the host, rather than the environment, is what differentially affects the development of late blight on petunia and that $P$. infestans is not able to exploit petunia tissue to the extent that it can exploit potato or tomato tissue. From another study, we know that the White Madness cultivar used in this study is similar in susceptibility to many other petunia cultivars (2).

Recent cases of petunia and tomato late blight in commercial greenhouses suggest that late blight-infected petunia plants, particularly those shipped into a greenhouse from other geographic regions, could be an important source of inoculum to tomato plants in the greenhouse $(3,7)$. The practice of producing petunia bedding plants and tomato transplants in the same greenhouse is common in the northeastern United States; half of the respondents ( 6 of 12) to a survey conducted by our lab grew petunia and tomato plants together. Furthermore, during the spring bedding plant production season, all of the growers surveyed maintained their greenhouses at temperatures conducive to late blight infection and development. Over half of those surveyed held their greenhouses at temperatures $\left(18\right.$ to $\left.21^{\circ} \mathrm{C}\right)$ that are within the range for optimum establishment of $P$. infestans on petunia and tomato. It is assumed that the moisture requirements for late blight also would be met, considering the high humidity conditions typically encountered from time to time in a northeastern greenhouse during the spring.

Bedding plant growers should be aware of the possibility of late blight on petunia and tomato plants during spring production. Understanding the environmental requirements of petunia late blight is an important step in understanding its epidemiology and provides the foundation for 
developing cultural control recommendations.

\section{ACKNOWLEDGMENTS}

We thank L. Bork at Ball Seed (Chicago) for kindly providing petunia seed, P. Becktell for his technical assistance, and J. Andrade-Piedra and the two anonymous reviewers for their critical review of this manuscript.

\section{LITERATURE CITED}

1. Andrade-Piedra, J. L., Hijmans, R. J., Forbes, G. A., Fry, W. E., and Nelson, R. J. Simulation of potato late blight in the Andes I: Modification and parameterization of the LATEBLIGHT model. Phytopathology. In press.

2. Becktell, M. C. 2005. The host-pathogen interactions and epidemiological implications of the Petunia $\times$ hybrida, Calibrachoa $\times$ hybridus and Nicotiana benthamiana-late blight systems. Ph.D. thesis, Cornell University, Ithaca, NY
3. Becktell, M. C., Daughtrey, M., and Fry, W. E. 2003. Beware of late blight on petunias and tomatoes. Greenhouse Business June 2003:3132.

4. Berg, A. 1926. Tomato Late Blight and Its Relation to Late Blight of Potato. West Virginia University Agricultural Experiment Station, Morgantown.

5. Caten, C. E., and Jinks, J. L. 1968. Spontaneous variability of single isolates of Phytophthora infestans. I. Cultural variation. Can. J. Bot. 46:329-348.

6. Crosier, W. F. 1933. Studies in the Biology of Phytophthora infestans (Mont.) de Bary. Cornell University, Ithaca, NY.

7. Deahl, K. L., and Fravel, D. R. 2003. Occurrence of leaf blight on petunia caused by Phytophthora infestans in Maryland. Plant Dis. 87:1004.

8. Derie, M. L., and Inglis, D. A. 2001. Persistence of complex virulences in populations of Phytophthora infestans in western Washington.
Phytopathology 91:606-612.

9. Hamrick D. 2003. Ball Redbook, 17tb ed. Vol 2: Crop Production. Ball Publishing, Batavia, IL.

10. Hartill, W. F. T., Young, K., Allan, D. J., and Henshall, W. R. 1990. Effects of temperature and leaf wetness on the potato late blight. N. Z. J. Crop Hortic. Sci. 18:181-184

11. James, W. C. 1971. An illustrated series of assessment keys for plant diseases, their preparation and usage. Can. Plant Dis. Surv. 51:3965.

12. Mizubuti, E. S. G., and Fry, W. E. 1998. Temperature effects on developmental stages of isolates from three clonal lineages of Phytophthora infestans. Phytopathology 88:837843.

13. Platt, H. W. 1999. Response of solanaceous cultivated plants and weed species to inoculation with A1 or A2 mating type strains of Phytophthora infestans. Can. J. Plant Pathol. 21:301-307. 